\section{FRI0691 DISCREPANCY BETWEEN THE EFFICACY OF BIOLOGICAL DMARDS BASED ON RANDOMIZED CONTROLLED TRIALS AND THE EFFICACY OF BIOLOGICAL DMARDS IN REAL-WORLD SETTINGS IN PATIENTS WITH RHEUMATOID ARTHRITIS: A STUDY USING THE IORRA COHORT}

Eri Sugano $^{1}$, Eiichi Tanaka ${ }^{1}$, Eisuke Inoue ${ }^{1}$, Mai Abe ${ }^{1}$, Mika Kawano $^{1}$, Kumiko Saka ${ }^{1}$, Naohiro Sugitani ${ }^{2}$, Yoko Shimizu ${ }^{1}$, Moeko Ochiai ${ }^{1}$,

Rei Yamaguchi ${ }^{1}$, Naoki Sugimoto ${ }^{1}$, Katsunori Ikari ${ }^{1}$, Ayako Nakajima ${ }^{2}$, Atsuo Taniguchi', Hisashi Yamanaka'. 'Institute of Rheumatology Tokyo Women's Medical University, Tokyo, Japan; ${ }^{2}$ Mie University Hospital, Center for Rheumatic Diseases, Mie, Japan

Background: Randomized controlled trials (RCTs), which are currently considered to provide the highest level of evidence, include patients with high disease activity and exclude those with comorbidities often seen in the real world. With the increasing recognition of the importance of real-world evidence, attention is being paid to discrepancies between RCT-based evidence and the patient population in routine clinical practice; however, few reports assessing these gaps in the context of rheumatoid arthritis $(\mathrm{RA})$ are available.

Objectives: We investigated the discrepancy between the efficacy of biological DMARDs (bDMARDs) in RCTs and the effectivenessof bDMARDs in routine clinical practice in patients with RA based on the IORRA cohort.

Methods: The effectiveness of bDMARDs (etanercept [ETN; $n=33$ ], golimumab [GLM; $n=20$ ], certolizumab [CZP; $n=17$ ], abatacept [ABT-subcutaneous injection \{sc\}; $n=14]$, and tocilizumab [TCZ-sc; $n=24]$ ) in RA patients who newly initiated bDMARD therapy in our hospital in 2016 was compared with the efficacy reported in phase 2 or 3 trials $(8$ total RCTs: ETN, 1; GLM, 2; CZP, 2; ABT, 1; TCZ, 2) during the RCT's observational periods. Effectiveness was evaluated by percentages of patients achieving ACR20, ACR50, and ACR70 and clinical remission based on DAS28 remission criteria using the IORRA cohort database. We also compared treatment responses between IORRA eligible and non-eligible patients in the MATSURI study, a phase 2 trial that evaluated TCZ-sc efficacy and safety and had relatively lenient inclusion criteria, since some RA patients in the IORRA cohort belonged to both the eligible and non-eligible groups.

Results: In 7 RCTs (excepting the MATSURI study), very few patients fulfilled the IORRA inclusion criteria (Table). The ACR achievement rates were higher among patients in RCTs, while remission rates were higher among IORRA patients (Table). The average DAS28 at baseline in the RCTs group was significantly higher than that in the IORRA group (Table). In the MATSURI study, 13 of 24 patients who newly initiated TCZ-sc met the inclusion criteria in the IORRA. Although the percentages of patients achieving ACR20, ACR50, and ACR70 and clinical remission among eligible patients were similar to those of patients in the MATSURI study, those of non-eligible patients were lower than those of MATSURI patients (Table). This indicates better effectiveness in eligible patients than in non-eligible patients.

Conclusion: Although RA patients in RCTs experienced a better ACR achievement rate than those in routine practice, clinical remission was difficult to achieve. This might be due to the difference in disease activity at the time of bDMARD introduction, suggesting that it is necessary to interpret the efficacy of RCTs based on differences in patient background.

\section{REFERENCES:}

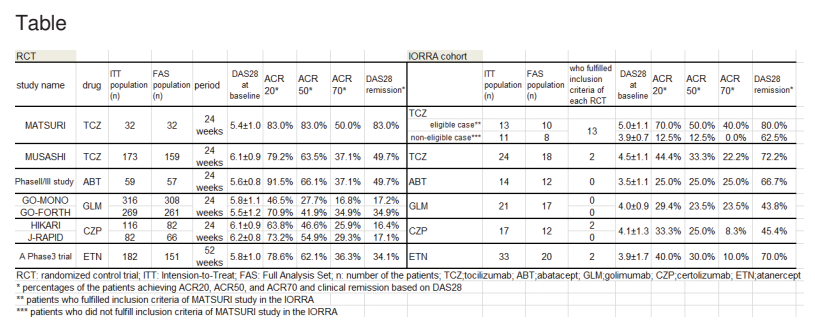

Disclosure of Interests: Eri Sugano: None declared, Eiichi Tanaka Speakers bureau: Abbvie, Asahi Kasei pharma co., Bristol Myers Squibb, Chugai Pharmaceutical, Daiichi Sankyo Co., Eisai Pharmaceutical, Janssen Pharmaceutical K.K., Nippon Kayaku, Pfizer, Takeda Pharmaceutical, Taisho Toyama Pharmaceutical Co., and UCB Pharma., Eisuke Inoue: None declared, Mai Abe: None declared, Mika Kawano: None declared, Kumiko Saka: None declared, Naohiro Sugitani: None declared, Yoko Shimizu: None declared, Moeko Ochiai: None declared, Rei Yamaguchi:
None declared, Naoki Sugimoto: None declared, Katsunori Ikari: None declared, Ayako Nakajima Grant/research support from: Asahi Kasei pharma co., Chugai Pharmaceutical, Daiichi Sankyo Co., Pfizer, Kissei Pharmaceutical Co., and Mitsubishi Tanabe Pharma Corporation., Atsuo Taniguchi: None declared, Hisashi Yamanaka Grant/research support from: AbbVie, Eisai, Bristol-Meyers, Novartis, Behringer, Astellas, Kaken, Nippon-Shinyaku, Pfizer, UCB, Ayumi, Ono, Daiichi-Sankyo, Taisyo-Toyama, Takeda, Tanabe-Mitsubishi, Chugai, Teijin Pharma, Torii, YLbio, Speakers bureau: Bristol-Meyers, Astellas, Pfizer, Daiichi-Sankyo, Takeda, TanabeMitsubishi, Chugai, Teijin Pharma, YLbio

DOI: 10.1136/annrheumdis-2019-eular.6589

\section{FRI0692 34. REHABILITATION HUMAN PAPILLOMA VIRUSSCREENING AND CHRONIC INFLAMMATORY ARTHRITIS: AN AUDIT}

Ernesto Tovar-Sugrañes ${ }^{1}$, Blanca Vidal-Alejandre ${ }^{2}$, Raquel López-Poza ${ }^{2}$, Mariano Andrés ${ }^{1,2}$, Maria Paz Martínez-Vidal ${ }^{1}{ }^{1}$ Hospital General Universitario de Alicante-ISABIAL, Seccion de Reumatologia, Alicante, Spain; ${ }^{2}$ Universidad Miguel Hernandez, Alicante, Spain

Background: Patients with autoimmune diseases suffer from an immunosuppressive state related to a pro-inflammatory environment and therapies received. Immunosuppression is a known risk factor for developing virusassociated cancers, including at uterine cervix $(1,2)$. One of the major risk and prognostic factors for cervical neoplasm is missing the screening and early detection programs of human papilloma virus (HPV) (3). This screening is recommended for immunosuppressed women to be performed annually between 21 and 65 years of age (4).

Objectives: To audit the degree of adherence to HPV-cervical cancer screening of patients with chronic arthritis in the rheumatology unit of a tertiary center.

Methods: A descriptive, cross-sectional study was performed. The medical records of adult, female patients, with clinical diagnosis of rheumatoid arthritis (RA) and psoriatic arthritis (PsA), being followed in rheumatology clinics were reviewed. Assistance to screening clinics and cervical cytology and HPV-PCR results were revised to determine if patients had followed the screening program. Type of screening, number of visits and findings were also collected. A descriptive analysis is presented, with an estimate of the $95 \%$ confidence interval $(95 \% \mathrm{Cl})$ for the primary study variable.

Results: 233 medical histories (144 AR, 89 PsA) from patients with a median age of 55 years (p25-75 18-60) were included. Information related to the performance of cervical screening was found in the clinical records of 137 patients $(58.8 \%, 95 \% \mathrm{Cl} 52.4-64.9 \%)$. Regarding the type of arthritis, the prevalence of performing cervical screening in RA and PsA was $60.4 \%$ and $56.2 \%$, respectively, while rates of women attending the program at least twice were $45.1 \%$ for RA and $37.1 \%$ for PAs. In relation of screening findings, HPV infection was detected in 8 patients $(5.8 \%)$, cervical dysplasia in $6(4.4 \%)$, while no case of invasive cancer was detected.

Conclusion: Autoimmune and inflammatory diseases, along with the treatment employed, are associated with an increased risk of cervical HPV infection. Despite this, information regarding HPV cervical screening was collected in only half of patients. Both patients and their treating rheumatologists must be aware of this risk and adhere to cervical screening programs to achieve an early diagnosis and management.

\section{REFERENCES:}

[1] JAMA.2006;296:2823. 2) Int J Cancer.2013;132:1429. 3) Int J Cancer.2012;130:937. 4) Rev.Esp.Patol.2014;47(1):1-43.

Disclosure of Interests: None declared

DOI: 10.1136/annrheumdis-2019-eular.5536 